University of Wollongong

Research Online

Faculty of Commerce - Papers (Archive)

Faculty of Business and Law

$1-1-2003$

\title{
The role of interpersonal communication in the development of client trust and closeness in a SME professional services context
}

Les Kirchmajer

University of Wollongong, lesk@uow.edu.au

Paul Patterson

University of New South Wales

Follow this and additional works at: https://ro.uow.edu.au/commpapers

Part of the Business Commons, and the Social and Behavioral Sciences Commons

\section{Recommended Citation}

Kirchmajer, Les and Patterson, Paul: The role of interpersonal communication in the development of client trust and closeness in a SME professional services context 2003, 1-12.

https://ro.uow.edu.au/commpapers/805

Research Online is the open access institutional repository for the University of Wollongong. For further information contact the UOW Library: research-pubs@uow.edu.au 


\title{
The role of interpersonal communication in the development of client trust and closeness in a SME professional services context
}

\author{
Abstract \\ This study develops and tests a model of effective interpersonal communication as an antecedent to \\ client trust and closeness amongst small to medium enterprise (SJ 1E) professional services \\ providerspersonal fmancial planners. A new multidimensional scale for interpersonal communications is \\ developed and tested, resulting in the identification of three dimensions : Communications clarity (5 \\ items),Social communications (4 items), and Information provision ( 7 items). Client trust is investigated \\ also as a multidimensional construct with credibility trust and benevolence trust being the two \\ dimensions used. Closeness is investigated as a unidimensional construct. The results suggest that there \\ is a positive relationship between communications clarity and, credibility trust and closeness; social \\ communications and benevolence trust and closeness. These findings would be beneficial for SME \\ professional services providers, as it would allow them to develop focused interpersonal communications \\ strategies to enhance their clients' perceptions of the trust and closeness. Increased client perception of \\ trust and closeness is beneficial as it leads to increased referrals and positive word-of-mouth \\ recommendations and mutually beneficial long-term relationships

\section{Keywords} \\ services, professional, context, trust, role, development, interpersonal, sme, closeness, client, \\ communication

\section{Disciplines} \\ Business | Social and Behavioral Sciences

\section{Publication Details} \\ Kirchmajer, L. \& Patterson, P. (2003). The Role of Interpersonal Communication in the Development of \\ Client Trust and Closeness in a SME Professional Services Context. In J. Lowe (Eds.), Small Enterprise \\ Association of Australia and New Zealand 16th Annual Conference Ballarat, Australia: University of \\ Ballarat.
}




\title{
The Role of Interpersonal Communication in the Development of Client Trust and Closeness in a SME Professional Services Context
}

\author{
A paper for the Small Enterprise Association of Australia and New Zealand $16^{\text {th }}$ Annual Conference,
} Ballarat, 28 Sept-1 Oct, 2003.

\author{
Les Kirchmajer \\ University of Wollongong \\ les_kirchmajer@uow.edu.au \\ Professor Paul Patterson \\ University of NSW \\ School of Marketing \\ p.patterson@unsw.edu.au
}

Graduate School of Business and Professional Development

\begin{abstract}
This study develops and tests a model of effective interpersonal communication as an antecedent to client trust and closeness amongst small to medium enterprise (SME) professional services providers personal financial planners. A new multidimensional scale for interpersonal communications is developed and tested, resulting in the identification of three dimensions : Communications clarity (5 items), Social communications (4 items), and Information provision ( 7 items). Client trust is investigated also as a multidimensional construct with credibility trust and benevolence trust being the two dimensions used. Closeness is investigated as a unidimensional construct. The results suggest that there is a positive relationship between communications clarity and, credibility trust and closeness; social communications and benevolence trust and closeness. These findings would be beneficial for SME professional services providers, as it would allow them to develop focused interpersonal communications strategies to enhance their clients' perceptions of the trust and closeness. Increased client perception of trust and closeness is beneficial as it leads to increased referrals and positive word-of-mouth recommendations and mutually beneficial long-term relationships
\end{abstract}




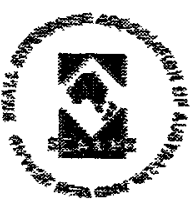

$16^{\text {th }}$ Annual Conference of Small Enterprise Association of Australia and New Zealand,

28 September - 1 October 2003

\title{
The Role of Interpersonal Communication in the Development of Client Trust and Closeness in a SME Professional Services Context
}

\begin{abstract}
Introduction
The aim of this research is to (a) develop and operationalise a measure of communication effectiveness and (b) to determine to what extent communication effectiveness impacts on clients' perceptions of trust and closeness in their relationship with their financial advisor.

Essentially this paper argues that Small to Medium Enterprise (SME) professional service providers personal financial planners, can use communication effectiveness as a key driver to (a) build trust and (b), to develop closeness to enable them to retain their clients and enhance their clients' perceptions of their services. The theoretical underpinnings of the model tested here lies in the relational paradigm (Gummesson (1994, 1997), Morgan and Hunt (1994); and communications theory (Duncan \& Moriarty (1998). The pivotal role of communications effectiveness in impacting trust and relationship commitment has not previously been examined in any depth (Duncan \& Moriarty (1998); Sharma \& Patterson (1999). Hence the contributions of this paper are to develop a scale of communications effectiveness in a professional services context, and then empirically examine it's impact in generating trust and closeness with a professional service provider.
\end{abstract}

\section{The SME Context}

The context of this study is the small to medium enterprise (SME), as this sector plays an important part in economic activity in Australian society. The Australian Government supports this view when it commented that there was an "increasing interest in the role of small and medium enterprises. As a group they contribute significantly to gross domestic product." (Department of Industry, Science \& Tourism, 1997, p.2.). The Australian definition of a 'small business' used in this study is "that the maximum number of employees is 100 for manufacturing firms and 20 for all others." (Reynolds, Williams \& Savage, 2000, p.4,). SMEs have different characteristics and circumstances from larger firms and should not be considered just as a smaller or 'shrunken' version of a large organisation. Marketing and management techniques that might be appropriate for large firms usually cannot be easily applied and be expected to work for a variety of reasons in a SME context.

Research in the SME services sector has been limited, especially in the professional services subsector.

\section{The Professional Services Context}

The context of this study is categorised in Lovelock et al.s' (2001) typology of service types as professional services. More specifically, 'people directed' (Lovelock, 1983) professional services. In particular, the study investigates the relationship between personal financial planners and their clients. This context is important due to the rapid growth of this sector.

The Australian Government Minister for Financial Services supports the view that the client need for financial planning services has been increasing rapidly when he commented recently that: "the financial planning industry is one of the fastest growing industries worldwide, reflecting the desire of people to become financially self sufficient." (Hockey, 1999, p.1.)

These personal financial services typically include the following, financial planning advice, investment planning advice, retirement planning advice, estate planning advice, superannuation and rollover strategies, information on social security and taxation benefits, insurance advice (AMP, 2000, p.3), financial plan preparation, portfolio management, investing in shares, money market investments, managed funds and other similar types of services.

This paper reports preliminary empirical findings from parts of a larger study into relationship marketing and management for SME professional services. This research is one of the few that views the relationship from a client's perspective. 
Whilst the context of this research is SME financial planner professional service providers, it is likely the findings can be generalised to other SME professional services such as engineering, project management, architecture, dentistry and medical para-professionals. SME professional service such as these share common and relevant characteristics such as, a high degree of service customisation, a high degree of technical complexity and a high degree of client involvement. Usually these professional services are expensive.

SME professionals often know quite a lot about their clients and have special and at times, close relationships with them. Clients of professional services providers often lack the requisite technical knowledge, skills, background or expertise in the specific area of interest or concern. Often they cannot diagnose their own needs, or discriminate between the range of possibilities or alternatives available to them. Professional services such as personal financial planning are said to have 'high credence properties' where, due to client's lack of technical expertise, it is intrinsically difficult for most clients to confidently evaluate the quality of the services they have received even after delivery and 'consumption' (Sharma \& Patterson 1999)

\section{Model}

The following diagram Figure 1.1, shows the model considered in this study and focuses on Interpersonal Communication and its antecedent relationship with Trust and Closeness.

\section{Figure 1.1}

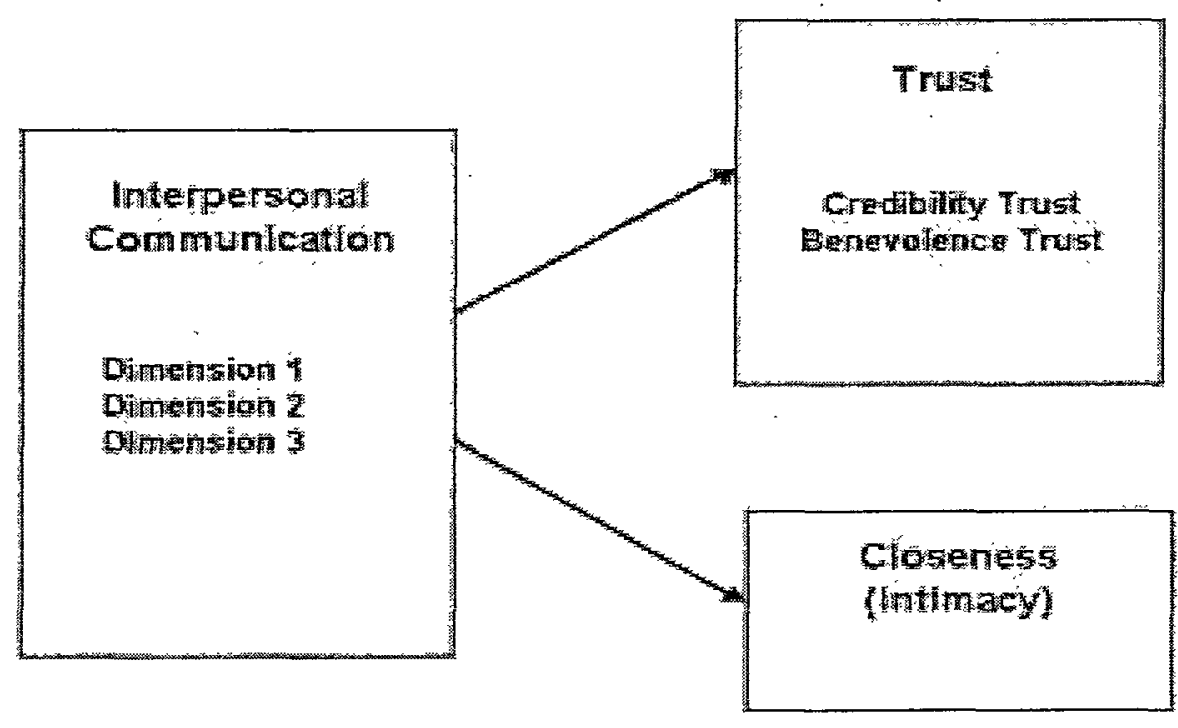

\section{Interpersonal Communication}

The study of interpersonal communication is fundamental to any study of relationships and in particular in the context of this study into relationship marketing. (Andersen, 2001; Barnes, 2001, p.148). Mohr and Nevin (1990) suggested that communication was 'the giue' that held the relationship together. In this study we use Andersen's (2001, p.168) definition of communication as "the human act of transferring a message to others and making it understood in a meaningful way." Duncan \& Moriarty (1998) suggest that it is impossible to have relationships without communication. We concur with their view that "communication is the human activity that links people together and creates relationships."(p.3). 


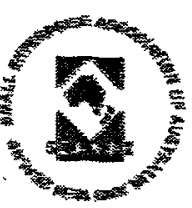

$16^{\text {th }}$ Annual Conference of Small Enterprise Association of Australia and New Zealand,

28 September - 1 October 2003

The key focus of this research is interpersonal communication effectiveness as it plays a key role in understanding of both the client and their financial planner's intentions and capabilities, thus forming the groundwork for the development of long-term client-service provider relationships. In this particular case, we look at he role of communication in the development of trust and closeness between the parties. A number of researchers contend that communication is a prerequisite for building trust among exchange partners. (Anderson \& Narus, 1990; Mohr and Nevin, 1990; Andersen, 2001)

In the study of relationship marketing and management, communications has received only limited attention. (Andersen, 2001; Duncan \& Moriarty, 1998) This suggests the critical role of communications has not been fully understood. Communications theory adds the "notions of balance, symmetry and reciprocity (i.e. interactivity)" (Duncan \& Moriarty 1998, p.6), which has been lacking in earlier models of marketing in which the focus was more on one-way communication and anonymous transactions. The focus of this study is the two-way personalized and customised communication, where "dialogue with the customer takes centre stage in the trust-building process" (Andersen 2001, p.178)

Communication manifests itself in many forms such as information, signs and signals, and messages. "Messages are signs and signals that are composed of information." (Duncan \& Moriarty 1998, p.8) It is important that these messages, signs and signals that are being interchanged between clients and their financial planner are consistent so that trust can be built.

The communication of intentions is specifically linked to credibility trust. An individual is believed to be credible if they do as they say they will or convey information accurately. (Rotter, 1971; Schlenker et al., 1973) Therefore, it is argued, it is possible to anticipate their future behaviour and thus trust them.

\section{Trust}

Trust plays a critical role in developing a relationship with a service provider (Gwinner, Gremler \& Bitner 1998). In a financial planning services context, this is due to the inherent credence properties and complex and customised nature of the service that makes it difficult for many clients to determine their own investment options, and even later on, it is problematic whether they are able to confidently assess whether their financial returns were maximised. Clients in this vuinerable position have little alternative but to rely on their adviser. Clients often need to make judgments concerning the credibility and trustworthiness of their professional service provider and are motivated to continue the relationship when they have confidence in (and trust) the competencies and abilities of their financial planner. But if this trust should ever be in doubt, then so would the relationship.

During the 1990s there emerged two approaches to viewing trust - one as a unidimensional construct of credibility and the other as a multidimensional construct of credibility and benevolence. For this study, trust has been examined as a multi-dimensional construct and focuses mainly on the trust dimensions of credibility and benevolence. Ganesan (1994) as well as Doney and Cannon (1997) support this multidimensional approach.

In this study, it is proposed that credibility trust, from the client's perspective, be based upon a financial planner's, (a) expertise, experience and task specific competencies to perform the their role effectively, (b) reliability, dependability and predictability in the delivery of services, and (c) honesty and the intention and ability to keep promises (Ganesan \& Hess 1997). Benevolence trust might be described as the extent to which the client believes that the financial planner "has intentions and motives beneficial to the client when new conditions arise, conditions for which a commitment was not made." (Ganesan 1994, p.3) 
Credibility trust aspects has received considerable attention in the past and well known by most researchers in the field and won't be covered again here. However the social side of the relationship has received less attention, hence benevolence trust will be discussed further.

\section{Benevolence Trust}

The language root of benevolence comes from the Latin: benevolens: bene, well + volens, to wish, i.e. wishing well. Benevolence focuses on the motives and intentions of the financial planner and could be described as an inclination or tendency towards goodwill. (Rempel, Holmes \& Zanna, 1985; Larzelere \& Huston, 1980; Ganesan, 1994; Mayer, Davis \& Schoorman, 1995; Ganesan \& Hess, 1997) It is this 'desire to do good' and personal characteristics such as caring, being: kind, sympathetic, altruistic, and selfless which form the foundation of benevolence trust. This aspect of benevolence trust, which is linked to goodwill, was also a key part of Sako's (1992) economics view of trust; she called it 'goodwill trust'.

Benevolence trust certainly applies here, where financial planning is a highly intangible and high credence qualities service. Benevolence trust rests on the more general attributions that financial planner is "motivated by a concern for the well-being of the relationship itself rather than by the particular rewards one is presently able to provide." (Rempel, Holmes \& Zanna 1985, p.100) The addition of benevolence trust to credibility trust to form an overall view of trust is important because benevolence trust may even exist when the objective credibility of the financial planner is less than perfect. (Ganesan 1994)

\section{Closeness}

Closeness is a construct that sits comfortably with SMEs in particular. In a small business, the owner and their employees often encounter the same customers over a number of contacts and over time they get to know each other. Small professional services businesses seem to have a natural ability to get close to their clients and go on to build long-term relationships with them. Barnes (2001, p.180) reports from his focus group research that customers appreciate the way small business staff call them by their name and remember their preferences from visit to visit. Often the same customers will say, "they have no relationship with larger businesses because they feel they are just a number." Hence, Closeness is a form of intimacy.

Clients often feel that because they have gotten to know their financial planner over a period of time, they are more comfortable to reveal more about their personal lives. From the qualitative phase of our research of 147 accountant clients, $60 \%$ of these clients indicated that they had developed special close relationships with their accountant. The following quotations from these clients are examples of the attitudes and feelings that had developed. "Maria is more like a friend than an accountant" (Client No.21);

"I hope to stay his client for my lifetime" (Client No.54) and

"We just pray that our accountant and friend, Gregory ..., will like Peter Pan, live forever" (Client No.104).

These relationships, were more than just one-way, clients perceived that they were mutual, e.g. "We treat our accountant as a friend and are treated as such in return" (Client No.41). Beatty (1993) reported similar findings with her research with sales assistant-customer relations. She found in her context, that customers discussed relationships in social terms, e.g. "I just love her to death. And she is like a friend, I mean, you can get close to somebody that way." (Beatty 1993, p.3). These quotations and many others provide a rich sense of what may be happening in the SME clientprofessional service provider relationship and provide sufficient justification for the inclusion of the closeness construct in our model.

Barnes (2001, pp.132-133) suggests that "the closeness concept captures many of the emotional aspects of relationships" and that high intensity and strong emotions lead to close and enduring relationships that are more likely to continue into the future. This role of closeness in maintaining 


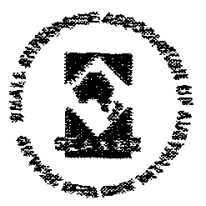

$16^{\text {th }}$ Annual Conference of Small Enterprise Association of Australia and New Zealand,

28 September -1 October 2003

longer-lasting relationships is very valuable for SMEs as it leads to referrals and word-of-mouth recommendations - a mainstay of successful SME marketing strategy in attracting new like-minded clients.

Beatty et al. 1996 indicated that strong close friendships were common, however most would not extend beyond the business contact situation and might be referred to as 'business friendships'. Caution is needed not to be carried away thinking that everybody wants a close relationship, as some research (Price \& Amould 1999 and Foumier et al. 1998) have suggested that not all clients want to establish close relationships with their financial planner.

Barnes, (1997, p.770) supports this caution when he commented that "What one customer may consider a warm, close friendly relationship, other will find stifling or unnecessary. They will prefer a more distant relationship, one characterized by much less warmth." This however should not be interpreted, as close relationships should not be strived for; indeed Barnes (2001, p.134) contends, "the conventional wisdom is correct that 'getting closer to the customer' is a good thing." He goes on to also contend, "the problem many companies and organizations encounter is that management has no idea how to increase that closeness." This study offers a possible solution, i.e. that certain factors of two-way interpersonal communications (communication clarity and social communications) would be useful as they are key elements in developing and maintaining closeness and hence close long-term relationships. (Duck, 1994; Barnes, 2001)

\section{Research Method}

A multi-phase approach was undertaken for this research. The first phase was exploratory, and qualitative in nature that helped to gain insights into the client-financial planner relationship. This stage was used to develop and confirm the model as well as the development of new measurement items for some of the constructs.

This qualitative phase consisted of two different approaches. The first approach involved the content analysis of letters (by two independent researchers) from 147 clients of 104 accountants, concerning their relationship with their accountant. The second approach consisted of 19 in-depth qualitative interviews that were recorded and transcribed and then content analysed. These interviews were conducted with clients of financial planning firms to gain an understanding of the antecedents of trust and closeness, as well as the dimensions of interpersonal communications.

The second phase consisted of a quantitative approach, utilising a cross-sectional survey using a selfadministered questionnaire design. The process undertaken included the development of the survey questionnaire instrument. For some constructs, existing measures found in the literature were used as is or slightly modified to suit the SME financial planner context. Some new measures were developed (as a result of the qualitative phases) - in particular for the construct of Interpersonal Communication.

The survey questionnaire underwent a pretest or pilot stage (49 usable out of 50 responses) for refinement and scale development before the large-scale distribution of the survey questionnaire. As a result of exploratory factor analysis five of the items for Interpersonal Communication were deleted, as they did not load cleanly on one factor. The final communications scale retained 26 measurement items from the original 31 items.

The final self-administered questionnaire yielded 325 responses (after 2 follow ups) from clients of financial planning firms. The net response rate was $36 \%$. Late respondents were not statistically significant from the early respondents on key constructs.

\section{Scale Development}

(a) Interpersonal Communication

This construct is not well established in management or marketing literature, and no scale could be found that was relevant to a professional services context. Hence we adopted Churchill's (1979) 
procedure for scale development. As indicated earlier 19 qualitative, in-depth interviews were conducted to gain an understanding of items that comprise excellent interpersonal communications. The final communications construct comprised 26 Likert items taken from Anderson, Londish \& Weitz (1987), Crosby \& Stephens (1987), Ruekert \& Walker Ir. (1987), Anderson \& Narus (1990), Moorman, Deshpande \& Zaltman (1993), Fisher, Maltz \& Jaworski (1997), Homberg (1998), Smith (1998) and Sharma \& Patterson (1999) and the qualitative interviews and content analysis of the 147 accountant client's letters. An exploratory factor analysis revealed 3 clean factors that together explained $69 \%$ of the variance. This was then subjected to a confirmatory factor analysis that supported the 3 factor solution (F1: Communications clarity (5 items), F2: Social communications (4 items), and F3: Information provision (7 items)). The final CFA solution demonstrated an acceptable fit $\left(\chi^{2}=278.7\right.$, df $=99$, AGFI $=0.915$, CFI $\left.=0.89\right)$ with all but one indicator having squared multiple correlations in excess of .50 (Gerbing \& Anderson 1988).

For the remaining constructs, multi-item scales were used in measuring respondents' credibility and benevolence trust, and closeness. To examine construct validity, we conducted exploratory factor analysis using orthogonal rotation (varimax) for the 9 items. Three factors emerged as expected, that cumulatively explained $67 \%$ of the variance. Factor analysis using oblique rotation (direct oblimin) produced similar factor patterns, confirming the discriminant and convergent validity of the measures (Rummel 1970). All items load highly on the appropriate factors and no item loaded greater than 0.40 on more than one factor, supporting the independence of the constructs. Cronbach alpha coefficients all exceeded 0.80 indicating good reliability.

Hence all six constructs (Communications clarity; Social communications; Informational provision; Credibility trust; Benevolence trust; and Closeness) exhibited construct, discriminant and convergent validity, and sound reliability.

\section{Results}

Table 1.1

Correlation Matrix of all Constructs

\begin{tabular}{|l|l|l|l|l|l|l|}
\hline Construct & $\mathbf{1}$ & $\mathbf{2}$ & $\mathbf{3}$ & $\mathbf{4}$ & $\mathbf{5}$ & $\mathbf{6}$ \\
\hline 1. Credibility trust & 1.0 & & & & & \\
\hline 2. Benevolence trust & .53 & 1.0 & & & & \\
\hline 3. Closeness & .60 & .76 & 1.0 & & & \\
\hline 4. Communications clarity & .62 & .68 & .84 & 1.0 & & \\
\hline 5. Information provision & .46 & .65 & .70 & .68 & 1.0 & \\
\hline 6. Social communications & .49 & .77 & .79 & .70 & .63 & 1.0 \\
\hline
\end{tabular}

While there are modest correlations between the constructs, the variance inflation factor (VIF) indicated multicollinearity was not a major issue.

A structural path model was then developed using AMOS 4 (Arbuckle and Wothke 1999) to antecedents of trust and closeness. The resultant path coefficients are shown in Table 1.2.

Table 1.2

Structural Model: Path Coefficients from Personal Communications to Trust and Closeness

\begin{tabular}{|l|l|l|}
\hline \multicolumn{1}{|c|}{ Path } & \multicolumn{1}{c|}{ Beta } & t value \\
\hline 1. Communications clarity $\rightarrow$ credibility trust & .653 & 11.7 \\
\hline 2. Communications clarity $\rightarrow$ benevolence trust & .152 & 2.3 \\
\hline 3. Communications clarity $\rightarrow$ closeness & .525 & 9.1 \\
\hline
\end{tabular}




\begin{tabular}{|l|l|l|}
\hline 4. Information provision $\rightarrow$ credibility trust & ns & \\
\hline 5. Information provision $\rightarrow$ benevolence trust & .159 & 2.8 \\
\hline 6. Information provision $\rightarrow$ closeness & .096 & 2.2 \\
\hline 7. Social communications $\rightarrow$ credibility trust & $\mathrm{ns}$ & \\
\hline 8. Social communications $\rightarrow$ benevolence trust & .590 & 9.2 \\
\hline 9. Social communications $\rightarrow$ closeness & .365 & 7.7 \\
\hline
\end{tabular}

Model fit statistics: $\chi^{2}=383.3$, df $143, p=.000$, GFI $=.891$ AGFI $=0.855$, CFI $=0.880$

Referring to Table 1.2, firstly the overall fit statistics of the structural model show that the three communications constructs do a good job of explaining why clients develop trust in their advisor, as well as a sense of closeness or intimacy. Next the findings show that communications clarity (i.e., the listening skills, enthusiasm, open and honest discussion) displayed by a financial planner when meeting with a client is far and away the strongest determinant $(\beta=0.653, \mathrm{p}<.000)$ of clients' perceptions of credibility trust (i.e., trust in the technical capabilities of the financial planner). Neither social communications nor information provision are significant in explaining credibility trust, although it should be pointed out that these constructs have modest correlations with credibility trust. In the structural model, it appears that they are 'washed out' in the presence of communications clarity.

Benevolence trust (i.e., faith that the financial planner will always act in your best interests and not act opportunistically) on the other hand is best explained by clients' perceptions of the social communications skills exhibited by financial planners $(\beta=0.590, p<.000$ compared to betas of .152 and .159 for communications clarity and information provision, respectively).

Closeness (clients perceptions of intimacy/closeness with their financial planner) was best explained by communications clarity $(\beta=0.525$. $\mathrm{p}<.000)$.

\section{Discussion of Findings}

This is one of the few studies that have demonstrated the key role that interpersonal communications plays in developing trust with providers of services high in credence properties - specifically high involvement, complex, highly customised professional services. Professional services such as financial planning services - the focus of this study, are intrinsically difficult for clients to evaluate in terms of technical quality. Clients simply do not have the technical expertise or specialist knowledge to evaluate whether a high quality core service has been provided. Very few clients of not only financial planning advice, but of the services provided by architects, accountants, solicitors or medical services, having the necessary knowledge or expertise to evaluate technical outcomes and hence trust in the provider. Trust has been shown in numerous studies to be a crucial necessary, (but not sufficient) condition for commitment and loyalty to a service provider. Since all SMEs professionals in today's competitive markets seek to generate repeat patronage and loyalty amongst their customer base.

The results of this study clearly indicate that interpersonal communications is a major determinant of trust between service professional (in this case financial planner) and client. The listening skills, enthusiasm exhibited, open and honest discussion (labeled Communications Clarity) go a long way to convincing the client that the financial advisor has the requisite technical/professional skills to capably invest a clients' money. In other words it is a major determinant of credibility trust - a critical ingredient in developing long term repeat client patronage. 
The informal transfer of information, discussions of a social nature and two-way communication (labeled Social Communications) go a long way to the convincing the client that their financial planner has a high level of goodwill towards them. In other words, that their financial planner's motives and intentions are friendly and that they will act in an altruistic manner in their ongoing relationship. The evidence suggests that 'social communication's is a major determinant of benevolence trust - a critical ingredient in developing affective component of a client's intention to stay with their financial planner.

This study also suggests that closeness between the client and their financial planner is driven by interpersonal communications. In particular, to major extent by Communication Clarity and to lesser extent by Social Communications. It is not surprising that the 'information provision' factor appears to play no significant role as closeness embodies an emotional aspect. Communication Clarity has items which relate to listening to the clients needs, keeping their information confidential, allowing them to get their ideas across, honesty in their communication and displaying enthusiasm in their communications - all of which would be beneficial in developing rapport and empathy with the clients. The addition of Social Communications to this mix supports the affective aspects of closeness.

This study has found that interpersonal communications can be thought of as having 3 dimensions - (i) communications clarity, (ii) social communications and (iii) informational provision. This information would be useful to SME professional service providers, as it would allow them to focus on communication strategies and actions which would increase the client's perception of trust and closeness they enjoy. Increased client perceived trust and closeness are beneficial in generating referrals and word-of-mouth recommendations (a major source of high quality new clients) and development of long-term close mutually beneficial relationships.

If the aim is to increase credibility trust, then focus on communications clarity. If the aim is to increase benevolence trust, then focus on social communications. That is, it would be useful to focus on different communications strategies to achieve the desired trust outcomes. Similarly if the aim is to increase closeness, then a focus on communications clarity would be beneficial, however social communications would also have a positive effect. 


\section{Bibliography}

AMP (2000), Advisory Services Guide, AMP Financial Planning Pty Ltd, Sydney, Australia.

Andersen, P.H. (2001), "Relationship Development and Marketing Communication: An Integrative Model," Journal of Business and Marketing, Vol.16, (3), 167-182.

Anderson, E., Londish, L.M. \& Weitz, B.A. (1987), "Resource Allocation Behavior in Conventional Channels," Journal of Marketing Research, Vol.24, (February), 85-97.

Anderson, J.C. \& Narus, J.A. (1990), "A Model of Distributor Firm and Manufacturer Firm Working Partnerships," Journal of Marketing, Vol.54, (1), 42-58.

Arbuckle, J.L. \& Wothke, W. 1999, Amos 4.0 User's Guide, SmallWaters Corporation, Chicago IL.

Barnes, J.G. (1997), "Closeness, Strength, and Satisfaction: Examining the Nature of Relationships between Providers of Financial Services and Their Retail Customers," Psychology \& Marketing, Vol.14, (8:December), 765-790.

Barnes, J.G. (2001), Secrets of Customer Relationship Management: It's all about how you make them feel McGraw-Hill, New York.

Beatty, S.E. (1993), "Relationship Selling in Retailing," Arthur Andersen: Retailing Issues Letters, Vol.5, (November: 6), 1-3.

Beatty, S.E.; Mayer, M.; Coleman, J. E.; Reynolds, K. E. \& Lee, J. (1996), "Customer-sales Associate Retail Relationships," Journal of Retailing, Vol. 72, (3), 223-247.

Churchill Jr., G.A. (1979), "A Paradigm for Developing Better Measures of Marketing Constructs," Journal of Marketing Research, Vol. XVI, (February), 64-73.

Crosby, L.A. \& Stephens, N. (1987), "Effects of Relationship Marketing on Satisfaction, Retention and Prices in the Life Insurance Industry," Journal of Marketing Research, Vol.24 (November), 404-411.

Department of Industry, Science \& Tourism (1997) in their Portrait of Australian Business, Results of the 1995 Business Longitudinal Survey, Small Business Research Program,

Doney, P.M. \& Cannon, J.P. (1997), “An Examination of the Nature of Trust in Buyer-seller Relationships," Journal of Marketing, Vol.61, (April), 35-51.

Duck, S. (1994) Meaningful Relationships, Sage, Thousand Oaks, Calif.

Duncan, T \& Moriarty, S.E. 1(998), "A Communication-Based Marketing Model for Managing Relationships," Journal of Marketing, Vol.62, (April), 1-13.

Fisher, R.J., Maltz, E. \& Jaworski, B.J. (1997), "Enhancing Communication Between Marketing and Engineering: The Moderating Role of Relative Functional Identification," Journal of Marketing, Vol.61, (July), 54-70. 


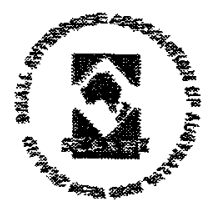

$16^{\text {th }}$ Annual Conference of Small Enterprise Association of Australia and New Zealand,

28 September -1 October 2003

Fournier, S., Dobscha, S. \& Mick, D.G. (1998), "Preventing the Premature Death of Relationship Marketing," Harvard Business Review, Vol.76, (January-February), 44.

Ganesan, S. (1994), "Determinants of Long-term Orientation in Buyer-Seller Relationships," Journal of Marketing, Vol.58, (April), 1-19.

Ganesan, S. \& Hess, R. (1997), "Dimensions and Levels of Trust: Implications for Commitment to a Relationship," Marketing Letters, Vol.8, (4), 439-448.

Gerbing, D.W. \& Anderson, J.C. (1988), “An Updated Paradigm for Scale Development Incorporating Unidimensionality and its Assessment," Journal of Market Research, Vol.25 (May), 186-192.

Gummesson, E. (1994), "Making Relationship Marketing Operational," International Journal of Service Industry Management, Vol.5, (5), 5-20.

Gummesson, E. (1997), "Relationship Marketing as a Paradigm Shift: Some Conclusions from the 30R Approach," Management Decision, Vol.35, (4), 267-272.

Gwinner, K.P., Gremler, D.D. \& Bitner, M.J. (1998), Relational Benefits in Service Industries: the Customer's Perspective," Journal of the Academy of Marketing Science, Vol.26 (2:Spring), 101-114.

Hockey, J. (1999), "Minister for Financial Services Launches Innovative New Program for Certified Financial Planners," Media Release 1 February 1999, (The Federal Minister for Finance and Regulation, Hon. Joe Hockey MP.)

Homberg, C. (1998), "On Closeness to the Customer in Industrial Markets," Journal of Business-toBusiness Marketing, Vol.4, (4), 35-69.

Larzelere, R.E. \& Huston, T.L. (1980), "The Dyadic Trust Scale: Toward Understanding Interpersonal Trust in Close Relationships," Journal of Marriage and the Family, Vol.42 (August), 595-604.

Lovelock, C.H. (1983), "Classifying Services to Gain Strategic Marketing Insights," Journal of Marketing, Vol.47, (3), 9-20.

Lovelock, C.H., Patterson, P.G. \& Walker, R.H. (2001), Services Marketing: An Asian Perspective, Prentice-Hall, Sydney.

Mayer, R.C., Davis, J.H. \& Schoorman, D.F. (1995), "An Integration Model of Organizational Trust," The Academy of Management Review, Vol.20, (3), 709-734.

Mohr, J. \& Nevin, J.R. (1990), "Communication Strategies in Marketing Channels: A Theoretical Perspective," Journal of Marketing, Vol.54, (October), 36-51.

Moorman, C., Deshpande, R. \& Zaltman, G. (1993), "Factors Affecting Trust in Market Research Relationships," Journal of Marketing, Vol.57, (January), 81-101.

Morgan, R.M. \& Hunt, S.D. (1994), "The Commitment-Trust Theory of Relationship Marketing," Journal of Marketing, Vol.58, (3), 20-38. 


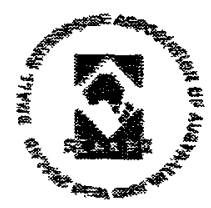

$16^{\text {th }}$ Annual Conference of Small Enterprise Association of Australia and New Zealand, 28 September -1 October 2003

Price, L.L. \& Arnould, E.J. (1999), "Commercial Friendships: Service Provider-Client Relationships in Context," Journal of Marketing, Vol.63, (4), 38-56.

Rempel, J.K., Holmes, J.G. \& Zanna, M.P. (1985), "Trust in Close Relationships," Journal of Personality and Social Psychology, Vol.49, (1), 95-112.

Reynolds, W., Williams, A. \& Savage, W. (2000), Your Own Business - A Practical Guide to Success, 3rd Ed., Nelson Australia, South Melbourne, Victoria, Australia

Rotter, J.B. (1971), "Generalized Expectancies for Interpersonal Trust," American Psychologist, Vol.26, (May), 443-452.

Ruekert, R.W. \& Walker Jr., O.C. (1987), "Marketing's Interaction with Other Functional Units: A Conceptual Framework and Empirical Evidence," Journal of Marketing, Vol.51, (January), 119.

Rummel, R.J. (1970), Factor Analysis, Northwestern University Press, Evanston, Ill.

Sako, M. (1992), Prices, Quality, and Trust: Inter-firm Relations in Britain and Japan, Cambridge University Press, Cambridge UK

Schlenker, B.R., Helm, B. \& Tedeschi, J.T. (1973), "The Effects of Personality and Situation Variables on Behavioural Trust," Journal of Personality and Social Psychology, Vol.25, 419427.

Sharma, N. \& Patterson, P.G. (1999), "The Impact of Communication Effectiveness and Service Quality on Relationship Commitment in Consumer, Professional Services," The Journal of Services Marketing, Vol.13, (2), 151-170.

Smith, J.B. (1998), "Buyer-Seller Relationships: Similarity, Relationship Management and Quality," Psychology \& Marketing, Vol.15, (1:January), 3-21. 